\title{
Developing Effective and Sustainable Distance Education Programs and Courses
}

\author{
Brian Hollenbeck and Qiang Shi
}

\begin{abstract}
In this article, we give an overview of the history and the ongoing effort of developing distance education programs and courses at Emporia State University. We carefully study ESU's Master's program in mathematics. This program is one of the most successful distance education programs at Emporia State University. It exemplifies the best practices in establishing and advancing such programs. The strategies of institutionalizing distance education programs and courses are also discussed.
\end{abstract}

Index Terms-Distance education, higher education, hybrid courses, online courses.

\section{INTRODUCTION}

Distance education has a long history that may be dated back to at least 250 years ago. Some researchers, such as Garrison [1] and Sumner [2], classified distance education into three generations by the technologies used in instruction and learning. Other researchers, such as Anderson and Dron [3], classified distance education by the development of pedagogical approaches. No matter how we look at the history of distance education, there is no doubt it has become more and more popular in the last ten to twenty years. There are many advantages of learning through distance education. Full-time employees appreciate the convenience and flexibility of such a learning environment. A large variety of online degrees and courses offer learning opportunities without geographical limitations. Free or low-cost online courses help make education more affordable to anyone who has Internet access. Because of these distinct features, distance education programs and courses are attracting more and more students.

Table I categorizes the number of students enrolled in degree-granting postsecondary institutions in the U.S. in Fall 2016 and Fall 2017. As defined by the U.S. Department of Education, a degree-granting institution grants associate's or higher degrees and participate in Title IV federal financial aid programs. As shown in the table, the number of postsecondary students in the United States decreased from 19,846,904 in Fall 2016 to 19,765,598 in Fall 2017. However over the same period, the number of students enrolled exclusively online or enrolled in some online courses both increased.

Distance education simultaneously provides challenges and opportunities for traditional higher education. On one hand, for-profit organizations had been taking advantage of

Manuscript received March 6, 2020; revised November 3, 2020.

The authors are with the Department of Mathematics, Emporia State University, Emporia, Kansas 66801, USA (e-mail: bhollenb@emporia.edu, qshi@emporia.edu). the emerging technologies to rapidly grow their distance education programs since the 1990s [5]. Some traditional institutions had been facing declining enrollment, partially due to the competition from those for-profit institutions. On the other hand, traditional colleges and universities realized that distance education could be an opportunity for them to reach out to a much broader range of students, especially adult learners. Thus, more traditional colleges and universities began to respond to this trend by investing in their own distance education programs and courses.

TABLE I: DEGREE-GRANTING POSTSECONDARY INSTITUTION ENROLLMENT DATA IN FALL 2016 AND FALL 2017

\begin{tabular}{|l|r|r|r|r|}
\hline \multirow{2}{*}{} & \multicolumn{4}{|c|}{ DATA IN FALL 2016 AND FALL 2017 } \\
\cline { 2 - 5 } & & & \multicolumn{4}{|c|}{ Number of students } \\
\cline { 3 - 5 } & Total & $\begin{array}{r}\text { No distance education } \\
\text { education } \\
\text { courses }\end{array}$ & $\begin{array}{r}\text { At least one } \\
\text { distance } \\
\text { education } \\
\text { course }\end{array}$ & $\begin{array}{r}\text { Exclusively } \\
\text { distance } \\
\text { education } \\
\text { course(s) }\end{array}$ \\
\hline $\begin{array}{l}\text { Fall } \\
2016\end{array}$ & $19,846,904$ & $13,541,976$ & $3,326,965$ & $2,977,963$ \\
\hline Fall & $19,765,598$ & $13,114,062$ & $3,548,036$ & $3,103,500$ \\
\hline
\end{tabular}

Source [4]: U.S. Department of Education, National Center for Education Statistics 2018. Digest of Education Statistics, Table 311.15

Distance education has an impact on almost all types of institutions, but the impact is probably more significant for regional universities. The research has found that, even though students in the distance education programs are typically not bound by the location of the institutions they are attending, most of those students choose to take online courses in their resident states. According to a survey conducted by Seaman, Allen, and Seaman at Babson Survey Research Group [6], "Distance enrollments remain local: 52.8 percent of all students who took at least one distance course also took a course on-campus, and 56.1 percent of those who took only distance courses reside in the same state as the institution at which they are enrolled."

How should an institution, especially a regional university with limited resources, embrace the opportunity of distance education and strategically establish, develop, and sustain effective online programs and courses? What are the key factors for such success? Those are the questions we are going to explore in this paper.

\section{OVERVIEW OF THE Distance EdUCATION PROGRAMS AT EMPORIA STATE UNIVERSITY}

Emporia State University (ESU) is a regional university in Kansas in the United States. The university was founded in 1839. Today, ESU has approximately 3100 undergraduate students and 2200 graduate students. 
ESU has a long history of high-quality and innovative teaching. It embraced online teaching many years ago. ESU's first distance education program was the Master's degree program in Health, Physical Education, and Recreation (HPER), which was established in 1996 and which was the first fully accredited distance learning Master's program in the United States. Since then, more distance education programs have been developed at ESU. Table II below summarizes the number of online graduate programs currently offered at the College of Liberal Arts and Science (LAS), the School of Business (SB), the School of Library and Information Management (SLIM), and the Teacher's College (TC), at ESU.

TABLE II: ONLINE PROGRAMS AT ESU

\begin{tabular}{|c|c|}
\multicolumn{2}{|c|}{ TABLE II: ONLINE PROGRAMS AT ESU } \\
\hline College & Number of Online Programs \\
\hline LAS & 7 \\
\hline SB & 4 \\
\hline SLIM & 4 \\
\hline TC & 17 \\
\hline
\end{tabular}

According to a recent report by Seaman and Seaman [7], ESU was ranked No. 7 both in distance enrollment and in distance enrollment growth among all public institutions in the State of Kansas. Distance education has been making a deep impact on the culture of our institution. The university leaders have created multiple incentive programs to encourage the creation of new online programs and courses. Faculty members have become more familiar with online teaching and have enjoyed working with students around the world. Students have become more willing to consider taking online courses. The IT Department has been investing in more resources to improve the infrastructure needed for online education. Overall, distance education programs have become one of the most important pillars to support ESU's mission.

\section{A CASE Study: Graduate Programs IN MATHEMATICS AT EMPORIA STATE UNIVERSITY}

The Department of Mathematics and Economics has been a pioneer of online teaching. In 2001, Dr. Joe Yanik, a professor of mathematics at ESU, piloted the first online math course, Number Theory. The course was taught as a purely online course via WebCT, a learning management system. Dr. Yanik developed a series of online tutorials as a vehicle to help students understand the course contents. He held weekly online meetings to answer student questions. Due to the limitation of technology at that time, no real-time audio or video communication could be utilized. Dr. Yanik, who is fast at typing, answered students' questions by typing answers at those online meetings.

Fast forward to 2019, the department now offers a Master's degree in Mathematics, Informatics-Quantitative Economics concentration, and a graduate certificate in mathematics. These degrees and certificate can be completed entirely online. In fact, the majority of our graduate students are distance students. As we can see from Fig. 1, in the last twelve years, the number of degree-seeking students in our
Master's program has increased by more than $1800 \%$.

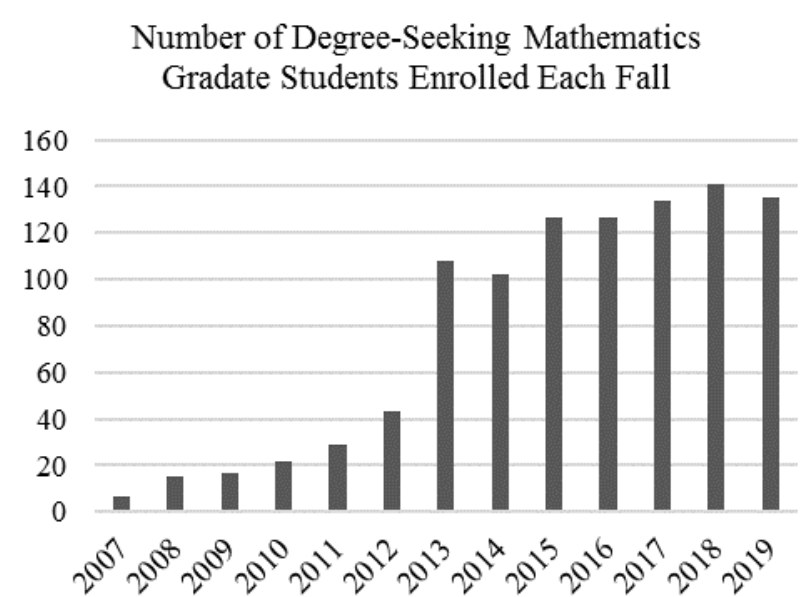

Fig. 1. Number of degree-seeking students in the master's program in mathematics at ESU.

Since 2016 we have enrolled more than 480 students into our graduate program. The online students account for more than $90 \%$ of all our graduate students. This growth has necessitated an increase in the number of online sections we offer each semester. Between 2007 and 2012, the department usually offered one or two online sections per semester. Now we often offer at least 12 sections each semester.

The faculty members collaborate diligently to bring great success to our online programs and courses. We describe a few important aspects in the following subsections.

\section{A. Degree Requirements}

Students in our M.S. program are required to complete 34 hours in total. Before graduation, students also need to pass a comprehensive exam and either complete a master thesis or give an oral presentation in a seminar. Non-degree-seeking students who want to pursue a certificate in mathematics are required to complete 18 hours. All these requirements can be fulfilled online, without physically being on campus.

\section{B. Course Settings}

To guarantee the quality of our courses, all the online sections in our graduate program are capped at around 20 students. Instructors may override the class capacity if they wish. All our graduate courses are taught directly by tenured or tenure-track faculty members without additional assistance from teaching assistants or graders. Team-teaching is used with new faculty to ease their transition into online instruction.

\section{Technology}

The quick development of technologies facilitated and advanced our department's efforts on online teaching. Over the last few years, the department gradually upgraded all our traditional classrooms into technology-enhanced classrooms. Each room contains a computer and multiple monitors. The university adopted Zoom, an online meeting software. Zoom has become the main platform for distance students to participate in online lectures and meetings. The instructors have the option to use Zoom or Panopto to record their lectures. Two faculty members in our department also secured internal funding and created a lightboard, which can be used to make recordings with special visual effects. 
To provide real-time lecture streaming, each room is equipped with an Osprey Video Capture card. Most faculty write on either a 27-in Wacom Cintiq tablet or a whiteboard that captures the handwritten notes via an Epson 3LCD projector. This method uses ActivInspire software and a special pen. When the instructor writes on the whiteboard, the movement of the pen is sensed, and digital ink shows on the board and the computer. This writing is saved on slides that can be saved as a PDF. Another option is to use a document camera that projects the writing of the instructor to both the front of the room and the online Zoom recording.

\section{Methods of Delivery}

The department offers two types of online courses: purely online and hybrid. In a purely online course, the instructor posts weekly study material (tutorials, recorded lectures, etc.) but does not provide live lectures. Students study the material and complete the required homework. In a hybrid course, the instructor will give lectures to on-campus students in a smart classroom. Distance students can either watch and participate in the lectures in real-time or watch the recordings later. The department does not mandate which format each course should use. We leave the decision to faculty members. According to historical data, approximately $45 \%$ of courses have been taught entirely online and the rest have been taught as hybrid courses.

\section{E. Student Participation}

Research, such as the study by Meyer [8], suggests online discussion has its own advantages and can encourage learning experiences. Therefore, we think it is crucial for all students to participate in course-related discussions, even in the online environment. Some instructors give bonus points to encourage students to ask or help with questions in Canvas' discussion forums. Many instructors hold online office hours to answer students' questions. Teamwork on homework or projects among students is acceptable by most instructors.

\section{F. Grading}

The university has been using Canvas, an online learning management system, for all online courses, since 2014. Typically, the instructors will ask students to submit their homework electronically as a Word, PDF, or LaTeX document. Some instructors take advantage of Canvas' built-in SpeedGrader to grade homework. SpeedGrader is a handy grading tool integrated with Canvas that allows instructors to annotate over the submitted documents, type comments, or record audio comments. Other instructors choose to download the homework files and grade homework problems on their Wacom Cintiq tablet.

\section{G. Exams and Proctoring}

Due to the nature of the discipline, almost all our math courses include some type of written exams. The exams taken by distance students are required to be proctored by a qualified proctor or a testing center. Prior to each exam, the corresponding course instructor sends the exam electronically to all proctors. Students take the exam under the supervision of their proctors. Once the exam is completed, the proctors are responsible to scan the entire exam and send it back.

The department has a policy to encourage students to take their exams at a testing center near them. However, we do provide some flexibility by allowing students to use individual proctors when students have difficulty finding a nearby testing center. Our proctoring policy helps guard the integrity of the tests and also enables distance students in rural areas to take our online classes.

\section{H. Other Distinct Pedagogical Methods}

Compared to the traditional college students, many distance students have unique academic background, interest, and needs. We have been trying to make extra effort to improve learning outcomes for these students. For example, similar to the concept of micro courses [9], Shi broke down long lectures into mini-lectures (each is about 15-20 minutes) for some of his online classes. These micro-recordings are more convenient for students to watch and have received good feedback. In addition, some of our instructors integrated free online resources, such as materials from massive online open courses, into their classes. The combination of different resources gives our students a high level of flexibility to study based upon their learning style. The same benefits have been observed by Neto [10] in his study. Moreover, our faculty members have always been working hard to communicate with students promptly. According to Al Ghamdi's study [11], lecturers' immediacy behaviors have very positive influence on students' learning outcomes. Another example is that we encourage students to select their seminar topics related to their career or academic interest. Doherty [12] concluded that this kind of authentic learning provided students with a positive learning environment, which is also what we observed from our online program.

\section{Program Assessment and Review}

The department periodically reviews and assesses our graduate programs and courses. A departmental graduate committee meets to discuss what areas need to be improved. The committee then brings its proposals to the department via an annual graduate program assessment forum. The department identifies areas of weakness and then sets up a plan to improve those areas. For example, a few years ago we implemented a plan to improve the enrollment process. In Spring 2019, we sent out a survey to our graduate students asking for feedback on the current enrollment process. Of the students who had experienced enrollment both before and after the change, $89 \%(25 / 28)$ preferred the new method of enrollment.

\section{FACTORS FOR INSTITUTIONALIZING DISTANCE EDUCATION PROGRAMS AND COURSES}

Creating and sustaining successful distance education programs and courses requires teamwork from faculty, administrators, IT staff and many other people on campus. We identify several important factors that help ESU achieve success in distance education.

\section{A. Leadership Team}

Having a leadership team that recognizes the importance 
of institutionalizing distance education is the first step toward such success. Well-established online programs and courses may help improve an institution's enrollment and academic reputation. However, it is not uncommon that some faculty members are skeptical or reluctant about online teaching. We recommend the institution leaders have honest conversations with their faculty regarding such a transformation. Institutionalizing distance education can only be successful when the administrators and the faculty share the same vision. Once the faculty members see how online programs help the institution with its mission and long-term growth, they will be more likely to support this movement.

\section{B. Infrastructure}

Developing necessary infrastructure to support online programs and online teaching will build the foundation for institutionalizing distance education.

Teaching online courses requires heavy use of technology. The hardware and software in the classroom may need to be upgraded. Universities and colleges may need more bandwidth, and their servers may need more storage capacity to hold hundreds of hours of recorded lectures. The faculty members may need more portable computers for grading and responding to students.

\section{Training}

Teaching online courses is very different from teaching face-to-face courses. It is a significant investment of time and effort to create an online course or transform a face-to-face course into an online course. Communication with students in different time zones or different countries provides new challenges even for the most experienced instructors in the traditional classroom. Grading online homework is very time-consuming. Therefore, institutions should provide appropriate training, supports, and incentives to their faculty. Technology training will help instructors become familiar with the use of new technologies. Instructional design workshops can provide step-by-step guidance to help instructors create their online course webpages. Given the growing number of students with disabilities in the U.S. [13], training on accessibility will increase the instructors' awareness of this issue and help them develop online educational materials that comply with the Individuals with Disabilities Education Act (IDEA) and other legal requirements.

\section{Incentives}

An internal incentive program that compensates faculty's extra work for creating online courses will encourage more faculty to participate in online teaching. When ESU began to institutionalizing distance education, the Office of Distance Education provided a credit-hour based stipend to instructors who created new online courses. When an online program is expanding and bringing in more students, overload pay to the faculty members who teach highly populated classes should also be considered.

\section{E. Marketing and Advertising}

Effective advertising is vital for the success of a new online program. The faculty in the program and the Marketing Department need to work together to determine the most effective and efficient marketing strategies. Online advertisements, such as Google Ads, can be very helpful. Our department's significant jump in enrollment in 2013 displayed in Fig. 1 can partially be attributed to marketing with Google Ads. However, Google Ads and other commercial online marketing tools are very expensive. Alternatively, getting help from alumni or using professional conferences to introduce new programs is low-cost and can also be effective.

\section{F. New Program Review}

Some new distance education programs may require additional resources such as funding for new equipment, additional lab space, or new salary lines for additional faculty and staff members. We recommend institutions to have a well-represented campus-wide committee to review those proposals and strategically direct resources to the programs that can have the biggest impact locally and globally.

\section{G. Quality of Academic Programs and Courses}

Online education does not mean sacrificing the quality of the program or the courses. Dr. Joe Yanik, the pioneer of our online program, used to say we offer “A Master's program that is available online" instead of "An online Master's program in mathematics." We are proud that our department is able to maintain a high academic standard when we convert more courses into online/hybrid courses. The feedback from our distance students is overwhelmingly positive. On a Spring 2019 survey, on a scale from 1 to $10,46 \%$ of respondents rated the program a " 10, , $30 \%$ rated us a " 9 ," $20 \%$ rated us an " 8 ," and only $4 \%$ rated us below an " 8 ." Another survey question asked if students agreed with the statement, "The classroom environment and technology were used effectively to promote learning." Out of 104 respondents, 89\% chose "Agree" or "Strongly Agree," yielding an overall average rating of 4.53 out of 5 . We conclude with an anonymous quote from our most recent comprehensive graduate student survey:

"I have taking [sic] all of my courses thus far with 5 different teachers. While they all have different teaching styles, they have all been WONDERFUL in their field. All have been very helpful when questions arise. They have made me think, but also helped me along when I'm really struggling. THANK YOU!!"

\section{SUMMARY AND CONCLUSION}

In summary, we reviewed the distance education programs and courses at Emporia State University. A careful study of ESU's Master's program in mathematics may help readers gain insightful details on how to execute a successful online academic program. We also offered some evidence-based strategies to other institutions who are thinking to start or improve their own online programs.

The dynamic evolvement of today's higher education requires all stakeholders in higher education to constantly reevaluate what we have been doing and make adaptive changes. Distance education has changed how people teach and learn. We welcome it and feel it is a rewarding experience. We encourage readers to explore many new 
teaching and learning opportunities only made possible through distance education.

\section{CONFLICT OF INTEREST}

The authors declare no conflict of interest of this submitted work.

\section{AUTHOR CONTRIBUTIONS}

$\mathrm{BH}$ and QS both conducted the research, analyzed the data, and contributed to the writing of the paper. Both authors had approved the final version.

\section{ACKNOWLEDGMENT}

We thank the following colleagues at ESU who provided the information for this article: Dr. Jerald Spotswood, Dean of Graduate School and Distance Education; Ms. Jenny Jiang, Distance Education Coordinator; Dr. Joe Yanik, Professor Emeritus of Mathematics.

\section{REFERENCES}

[1] G. R. Garrison, "Three generations of technological innovation in distance education," Distance Education, vol. 6, no. 2, pp. 235-241, 1985.

[2] J. Sumner, "Serving the system: A critical history of distance education," Open Learning, vol. 15, no. 3, pp. 267-285, 2000.

[3] T. Anderson and J. Dron, "Three generations of distance education pedagogy," International Review of Research in Open and Distance Learning, vol. 12, no. 3, pp. 80-97, 2011.

[4] U.S. Department of Education, National Center for Education Statistics 2018, Digest of Education Statistics, Table 311.15.

[5] A. I. Morey, "Globalization and the emergence of for-profit higher education," Higher Education, vol. 48, no. 1, pp. 131-150, 2004.

[6] J. E. Seaman, I. E. Allen, and J. Seaman, Grade Increase: Tracking Distance Education in the United States, 2018.

[7] J. E. Seaman and J. Seaman, Distance Education State Almanac, 2017.

[8] K. A. Meyer, "Student perceptions of face-to-face and online discussions: The advantage goes to ...," Online Learning Journal, vol. 11, no. 4, pp. 53-69, 2007.
[9] T. X. Hou, X. R. Gou, and Y. F. Gao, "Preliminary application of micro-course in distance education," International Journal of Information and Education Technology, vol. 6, no. 2, pp. 132-136, 2016.

[10] S. C. Neto, "Combining distance and traditional learning: A study of the use of virtual learning environment objects and massive online open courses in statistics class," International Journal of Information and Education Technology, vol. 7, no. 1, pp. 1-5, 2017.

[11] A. A. Ghamdi, "Influence of lecturer immediacy on students' learning outcomes: Evidence from a distance education program at a university in Saudi Arabia," International Journal of Information and Education Technology, vol. 7, no. 1, pp. 35-39, 2017.

[12] I. Doherty, "Delivering effective distance education through engaging students in authentic learning activities a learning design and longitudinal research results," International Journal of Information and Education Technology, vol. 1, no. 3, pp. 247-253, 2011.

[13] S. K. Oswal and L. Meloncon, "Paying attention to accessibility when designing online courses in technical and professional communication," Journal of Business and Technical Communication, vol. 28, no. 3, pp. 271-300, 2014

Copyright $(\odot 2021$ by the authors. This is an open access article distributed under the Creative Commons Attribution License which permits unrestricted use, distribution, and reproduction in any medium, provided the original work is properly cited (CC BY 4.0).

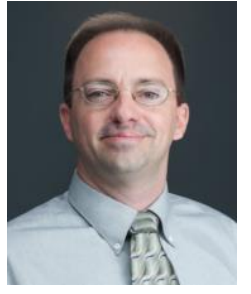

Brian Hollenbeck is a professor of mathematics and the chair of the Department of Mathematics and Economics at Emporia State University in the United States of America. He received his Ph.D., M.S. and B.S. degrees from the University of Missouri. His research interests include harmonic analysis and complex analysis, mathematical modeling, and innovation in teaching.

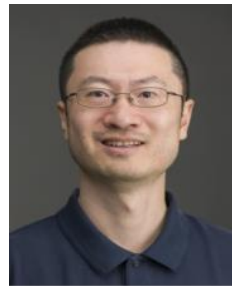

Qiang Shi is a professor of mathematics in the Department of Mathematics and Economics at Emporia State University in the United States of America. He received his Ph.D. from the University of Missouri, and his M.S. and B.S. degrees from Xi'an Jiaotong University. His research interests include harmonic analysis and partial differential equations, signal processing, and innovation in teaching. 